how rankings measure quality.

Wildavsky's style is gripping and urgent. Although he exaggerates the "irrelevance" of national boundaries in higher education visa restrictions, patent laws and constraints on security-related research all prove the continued relevance of borders in a knowledge economy - his point that the forces of globalization will profoundly shape the future of higher education cannot be ignored. Not everyone will share Wildavsky's faith that a "free trade in minds" will lead to equitable, or economically beneficial, outcomes. However, we must all grapple with his view that knowledge is a commodity, and universities, if they wish to survive, must treat it as such. Adam R. Nelson is associate professor of educational policy studies and history at the University of Wisconsin-Madison, Madison, Wisconsin 53715, USA.

e-mail:anelson@education.wisc.edu

\title{
Why fairness pays
}

\section{The Calculus of Selfishness \\ by Karl Sigmund \\ Princeton University Press: 2010. 192 pp. $\$ 35.00, £ 24.95$}

Why would two drivers caught in a snowdrift both shovel snow to clear a route, rather than wait for one to do it? Or, given $\$ 10$ to split with someone however you like provided they accept your offer, why are you more likely to give them $\$ 5$ than $\$ 1$ ? You could keep $\$ 9$, knowing that your ultimatum is better for them than the $\$ 0$ you would both get if they refuse. Why does it pay to be fair?

Understanding the evolution of cooperation is one of this century's foremost scientific challenges. It is also an exercise in game theory, the mathematical modelling of strategic interaction. Since 2000, several international meetings and multi-authored volumes have focused on the problem, and some consensus has emerged. Animals, especially humans, are far more cooperative than game theory has predicted. However, existing models exclude important factors, such as group dynamics and emotions, which are capable of sustaining commitments. We need a new kind of game theory to capture, among other things, variation in psychological traits, cultural forces and network structure.

Nevertheless, Karl Sigmund opts to "neglect" these three factors in The Calculus of Selfishness. It is a book about the old kind of game theory. Sigmund focuses on "simple models of social dilemmas", such as the 'snowdrift' and 'ultimatum' games mentioned above. In exploring "reciprocity between selfinterested individuals", he adopts a broad interpretation that includes third parties as potential donors or recipients of help. He demonstrates how concern for one's own reputation can help preserve norms of community or fairness, such as the fair split that is usually observed in ultimatum experiments. If I know that you reject unfair ultimata, then I will hesitate to propose one.

With collaborators from Vienna, Sigmund has pioneered the development of evolutionary game dynamics. This thought-provoking
"Animals, especially humans, are far more cooperative than game theory has predicted." book is a distillation of his many influential contributions to the field. It is a showcase of clever models and elegant mathematics, replete with sometimes counterintuitive insights. For example, the option to abstain from a joint effort when it seems unpromising can help to enforce cooperation based on sanctioning; and a selfish urge to exploit others, whenever one can get away with it, can boost the welfare of all by ensuring a supply of retaliators.

Sigmund's expansive introduction contains no equations. But a full appreciation of the remaining chapters demands significantly more than "a modicum of elementary mathematics". Nonetheless, the book will appeal to practitioners of behavioural or experimen-

tal economics, whose work suffuses the models; and to those who seek an upto-date assessment of how much progress the old kind of game theory has already achieved towards understanding cooperation.

The new kind of game theory, if it takes hold, will view strategically interacting populations as complex adaptive systems, and will rely increasingly on computer simulations. It will account for group, coalition and alliance formation across multiple scales of space, time and connectivity. It will also allow for personality to influence role and strategy in alliance-formation games, for example, the expected benefit of joining a group may be constrained by the perceived harmony of the resulting personality mix. Yet the new kind of game theory will never quite supplant the old, which when artfully used, as throughout Sigmund's book, affords insights that are hard to come by any other way.

Mike Mesterton-Gibbons is professor of mathematics at Florida State University, Tallahassee, Florida 32306-4510, USA, and author of An Introduction to Game-Theoretic Modelling.

e-mail:mesterto@math.fsu.edu

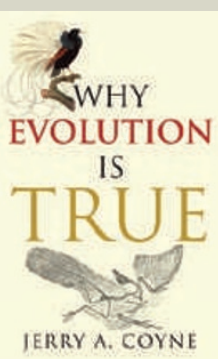

\section{Why Evolution Is True}

by Jerry A. Coyne (Oxford Univ. Press, E8.99)

Jerry Coyne demonstrates the strength of evolutionary biology in a clear and accessible manner. Reviewer Xu Xing wrote: "He uses multiple strands of data in such a clear and sometimes humorous way that an open-minded reader can hardly avoid learning a great deal about evolution: from feathered dinosaurs to vestigial organs." (Nature 462, 988; 2009.)

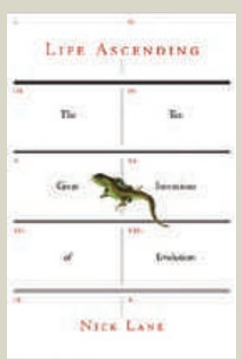

Life Ascending: The Ten Great Inventions of Evolution

by Nick Lane (Profile Books, $€ 9.99$ )

Nick Lane picks ten of evolution's key inventions - including sex, death and photosynthesis - to discuss how they arose, what they mean and why they revolutionized the living world. Wrote Lewis Wolpert of the hardback edition: "Not everyone will agree with his choice ... similar to life itself, the book is full of surprises." (Nature 460, 460; 2009.) 